\title{
OPINIÃO
}

\section{Uma análise da economia paranaense nas últimas décadas}

\author{
Demian Castro ${ }^{*}$ \\ Igor Zanoni Constant Carneiro Leão**
}

Ao fazer a síntese das intensas mudanças políticas, econômicas e sociais que ocorreram durante as décadas de oitenta e noventa no Brasil e envolveram todas as unidades da federação, inclusive o Paraná, os autores deste texto optaram por estilizar os fatos dentro de um cenário pessimista. A análise de conjuntura, em que pesem sua necessária perecibilidade, deveria depositar o olhar no médio e longo prazo, e um ponto de partida pessimista ajuda a não subestimar os desafios do porvir.

A análise de conjuntura proposta parte da idéia de que, nesse período, houve um processo de reestruturação selvagem da economia em virtude da abertura comercial e financeira e da estabilização com ancoragem cambial entre 1995 e 1999. A contundência desse ajuste repercutiu no mercado de trabalho trazendo precarização das condições laborais e desemprego. Este movimento, com impactos negativos no mercado interno, gerou nas mentes mais desavisadas a imagem de uma retomada da modernização pois cresceram as importações e muitas destas vieram a substituir insumos domésticos, o que daria maior competitividade aos produtores locais.

O país foi sugado pela onda de globalização produtiva e financeira, impulsionada em muitos países emergentes pela adesão irrestrita a paradigmas assentados na idéia de uma autonomia virtuosa do mercado para gerar crescimento e bem-estar para todas as camadas da população, independentemente de perda de soberania e fragilização do Estado. Este era visto como grande demais, vivendo uma crise que já se arrastava há algum tempo e que deveria ser, em parte privatizado em parte sujeito a uma forte disciplina fiscal e financeira que ditou a política macroeconômica daí para frente e tiraram de pauta aspectos como uma melhor distribuição de renda, democratização do solo urbano e rural e manutenção de uma mobilidade social que inclusive avalizasse politicamente a ação governamental.

No âmbito da economia e do setor público estadual, o exame das mudanças pode ser dividido em dois períodos. O primeiro, que vem desde as "grandes transformações" dos anos

* Doutorando em Economia pela Universidade Estadual de Campinas (UNICAMP). Professor do Departamento de Economia da Universidade Federal do Paraná (UFPR). Endereço eletrônico: demian@ 
setenta, atravessando os oitenta até meados dos noventa, mostra um ciclo de mudanças estruturais que perdem gradativamente dinamismo em virtude da crise da economia brasileira nas últimas décadas, que por um lado se deve a motivos endógenos e por outro reflete o instável panorama internacional.

Durante esse ciclo de mudanças, o setor público estadual, apesar do quadro de dificuldades, consegue manter suas partes constitutivas relativamente saudáveis e, portanto, com alguma capacidade de ação coordenada. Essas partes aludidas abrangem a área orçamentária das secretarias de governo, as empresas públicas estaduais e, finalmente o setor financeiro estadual no qual se destaca, entretanto, o fechamento do Banco de Desenvolvimento do Paraná (Badep) no início dos anos noventa.

Em alguma medida é possível afirmar que a articulação política permitiu elaborar e executar ao longo do tempo uma política estadual de desenvolvimento relativamente bem sucedida, responsável em certa medida pela manutenção do espaço estadual num "polígono regional de desconcentração concentrada" com modernização agrícola, certo adensamento industrial e sustentação dos serviços de infra-estrutura.

A partir da segunda metade dos anos noventa inicia-se um novo ciclo de mudanças, em geral caracterizadas pelo estabelecimento de novos vínculos produtivos, comerciais e financeiros externos e alguma desconexão dos canais de articulação com o mercado interno e as outras unidades federativas. Este movimento é acompanhado por mudanças profundas na estrutura do setor público estadual, que perde seu banco público estadual, abandona algumas importantes funções nos serviços de infra-estrutura através da privatização de empresas estaduais e outras modalidades de cessão de serviços ao setor privado e, por último, se afasta de alguns atributos históricos de disciplina fiscal, desequilibrando a área orçamentária.

Durante este período, a política estadual de desenvolvimento enveredou por uma via autônoma e agressiva: a guerra fiscal foi o instrumento largamente usado para atrair investimentos, principalmente da indústria automobilística. Portanto, o cenário pessimista do qual surge a análise de conjuntura refere-se às dificuldades atuais de desenhar uma ação pública estadual convincente no plano do desenvolvimento econômico e social sem partir para a guerra fiscal e sem os antigos apoios do Estado desenvolvimentista.

O processo de desenvolvimento envolve necessariamente consensos entre atores públicos e privados em torno de questões estratégicas e de longo prazo. A questão importante

\footnotetext{
** Doutor em Economia pela Universidade Estadual de Campinas (UNICAMP). Professor do Departamento de Economia da Universidade Federal do Paraná (UFPR). Endereço eletrônico: igorza@bol.com.br
} 
hoje é: como chegar a esses consensos pela via cooperativa sem o velho expediente da renúncia tributária? Quais políticas de desenvolvimento deveriam e poderiam ser executadas pelos governos estaduais dentro de um cenário maior em que o governo federal parece não assumir com o antigo vigor as iniciativas referentes ao desenvolvimento regional?

\section{O Paraná no cenário nacional e internacional}

No que diz respeito à inserção do Paraná nos cenários nacional e internacional cabe destacar que, no início dos anos 80, explicita-se uma crise internacional que arrasta a economia brasileira e põe fim ao longo ciclo de construção política e econômica de uma economia nacional cujo dinamismo estivesse em seu interior. Uma das faces dessa crise foi o colapso do crédito externo induzindo uma política econômica passiva diante dos credores internacionais e dos organismos que coordenam o financiamento e as políticas conseqüentes para a periferia.

Esse quadro implica em estrangulamento cambial, perda de competitividade da economia brasileira e crise fiscal e financeira do Estado, crescentemente em desvantagem na luta pela manutenção da moeda nacional e do valor contábil das empresas privadas. Observase que em meio à crise do Estado e da federação, couberam aos governos conduzir parte substancial do processo de democratização por serem destinatários, através das eleições, das demandas sociais ampliadas pela crise e as novas liberdades civis.

Nos anos 90, assiste-se a uma liberalização comercial e financeira como contra face de uma difícil renegociação da dívida externa e, também, a um novo ciclo de endividamento para pagar as importações liberadas pela valorização do câmbio numa "economia aberta". Este ajuste estabilizador levou a uma desestruturação do já debilitado aparelho produtivo público e privado, a uma desarticulação do mercado de trabalho com aumento da segregação social e fragmentação do espaço econômico nacional.

O mercado interno duramente constituído em décadas que alternaram autoritarismo e democracia encolheu e fragmentou-se em poucas ilhas ou anéis espaciais de prosperidade que, sobre o estímulo da guerra fiscal, procuravam fugir dos problemas de concentração e desigualdade da federação brasileira. Para os mais otimistas, o Paraná se constituía numa dessas ilhas.

Como assinalam autores como Macedo, Vieira e Meiners, a antiga idéia de uma complementaridade da economia paranaense em relação principalmente a São Paulo foi substituída pela visão de uma economia que compõe um dos elos de uma rede de núcleos 
dinâmicos que, por um lado está redefinindo o processo de criação de riqueza na economia brasileira e por outro está cada vez mais integrada e articulada com o exterior. Nesse caso se encontra especialmente a Região Metropolitana de Curitiba.

Esses autores enfatizam um conjunto de tendências que remetem aos seguintes problemas:

1) Tendência de a economia paranaense basear-se cada vez mais na expansão da indústria metal-mecânica e serviços associados, fortemente nucleados ambos na automobilística;

2) Criação de oportunidades para o desenvolvimento de fornecedores locais e impacto de novos investimentos sobre os serviços;

3) Avanço do agronegócio e constituição de funções urbanas em cidades de pequeno porte, criando um mercado de trabalho não apenas rural nos pequenos municípios;

4) Concentração das atividades econômicas na Região Metropolitana de Curitiba com tendência a reforçar um processo urbano de periferização excludente, na medida em que em seu entorno crescente abrem-se espaços de pobreza e precário uso do solo, entre outros aspectos;

5) Diferenciação do potencial dinâmico de cada região do estado, com as regiões mais urbanizadas dependentes do investimento industrial e as regiões ligadas ao agronegócio mais conectadas às exportações. Em ambas, o declínio da migração ocorre com fragmentação do espaço urbano, mesmo em cidades onde há algum tempo isso seria inesperado;

6) Desestruturação do mercado de trabalho com baixa elasticidade do investimento industrial sobre o emprego assalariado, crescimento da informalidade e desemprego estrutural em diversas faixas da população economicamente ativa, notadamente nos maiores centros urbanos e em sua periferia;

7) Crescimento baixo, mas contínuo da população, inclusive no interior, paralelo ao envelhecimento, levando a demandas novas sobre a agenda pública e aos mecanismos existentes de seguridade social;

8) Transformação na política pública originando um padrão mais descentralizado, horizontalizado e seletivo em termos espaciais e territoriais que, entretanto, está longe de dar conta dos graves problemas apontados, na medida em que consiste em focalização de ações públicas num ambiente de degradação espacial e social muito generalizado.

A combinação dessas tendências revela uma velha dicotomia do desenvolvimento brasileiro: o progresso material encontra-se descolado do bem-estar social de grandes 
segmentos da população e o dinamismo da economia não converge com o progresso social. Nessas condições, o ambiente para a realização de investimentos e expansão do consumo, com freqüência fica rarefeito, tornando menos denso o espaço econômico rebatendo sobre a vida e o consumo desses segmentos.

Fica claro a partir daí e dos trabalhos e pesquisas disponíveis sobre o Paraná, como os que têm realizado o Ipardes, o Dieese e o IBGE, que o desenvolvimento da economia brasileira nos termos acima tem permitido a presença de anéis de criação de riqueza, inclusive no Paraná, em virtude da estratégia de expansão de determinados oligopólios e de sua visão sobre o mercado nacional e sul-americano e, não menos importante, do senso de oportunidade dos policy makers locais.

Todavia, a existência destes anéis, além de carregar as informações genéticas do desenvolvimento excludente, não é capaz de dar sentido ao espaço nacional dramaticamente ocupado por anéis de privação e violência com extraordinária capacidade de difusão. Nesse sentido são limitados os impulsos ao crescimento da economia paranaense e brasileira a partir do Estado e do formato da política econômica, que realça uma subordinação passiva à concentração produtiva e financeira.

Esses impulsos têm vindo da vocação exportadora antiga do Brasil e mais particularmente do Paraná, tanto do agronegócio quanto do oligopólio automotivo da região metropolitana de Curitiba. Isso condiciona e limita o crescimento e o espaço de manobra do Paraná, especialmente quando o Estado está pagando dívidas da guerra fiscal passada.

Não há nesse contexto políticas de alto impacto sobre a pobreza e bem-estar e o tecido social paranaense passa a se caracterizar pela violência como um modo rotineiro de vida em quase todos os municípios e uma questão social difusa e de grande porte em virtude das condições materiais referidas, a uma cultura dominada pelo individualismo, a desinformação, que em grande medida caracteriza a mídia e a uma grande precarização de movimentos sociais e trabalhistas que sofreram impactos fortes com a crise social e no mercado de trabalho.

No conjunto da economia paranaense faz falta um agente financiador e articulador de projetos que induza ações empresariais como foi o caso do Badep, cuja rica experiência foi perdida sem deixar o lastro de sua memória técnica e política. Nos anos 90, proliferaram instâncias de negócios que desnacionalizaram ou privatizaram empresas deixando o governo estadual refém de contratos com segmentos do setor privado e com pouco espaço político 
para alavancar ou defender um projeto de governança mais coerente com os princípios de um modelo de desenvolvimento inteligente e socialmente equilibrado.

Mesmo o "novo moderno" que veio a instalar-se no Paraná como, por exemplo, as indústrias do setor automotivo poderiam, em tese, vir a constituir o cerne de uma cultura industrial, mas isso não ocorre porque não geram mais os antigos linkages da era fordista, seus vínculos espaciais e sociais podem desfazer-se rapidamente ao sabor do desmonte de uma linha de produção. Mal o núcleo automotivo instalou-se no Paraná e já é possível conviver com uma experiência de desmontagem de algumas de suas atividades produtivas.

Os espaços abertos à economia paranaense têm sido aqueles aproveitados pela política externa brasileira que tem soldado um pacto com países de rápido crescimento com uma política econômica original e bastante autônoma como a China e a Índia. Porém, isso é insuficiente para garantir o crescimento de uma economia diversificada e com o porte da economia brasileira no quadro de uma deterioração contínua da economia internacional, arrastando para baixo o investimento industrial o emprego e a renda, dado o recorte da política macroeconômica de juros altos, superávit primário elevado, câmbio estável numa verdadeira subordinação de todos os interesses aos interesses financeiros. Este quadro impacta, sobretudo, no Paraná, sobre seus maiores centros urbanos, fragmentando sua sociedade já historicamente necessitada de um espaço social e político mais abrangente.

Nesse contexto a questão das finanças federativas é crucial. É necessário pensar o estado no sentido de que o Paraná deixe de se considerar uma periferia dinâmica em favor de uma nação com muitas regiões cuja riqueza econômica e social precisa ser preservada e dinamizada. No contexto atual do Paraná, o mercado de trabalho cria poucos empregos, a massa salarial não sobe, a renda média se deteriora e o endividamento das famílias e empresas menores é geral, agravado pelos altos juros, pelo baixo dinamismo do mercado urbano e o difícil acesso ao sistema bancário.

Historicamente, o desenvolvimento regional do Paraná se fez a partir da reconstrução das velhas relações de produção e do baixo nível de renda das células exportadoras presentes até a década de 30, no sentido da criação de uma economia baseada no trabalho assalariado e em grande parte maximizando as possibilidades de dinamismo geradas pela economia paulista. Isso foi possível em grande parte graças a uma atuação do Estado e de suas antigas agências de fomento e de pesquisa, no quadro mais amplo de uma economia nacional em construção acelerada. 
$\mathrm{Na}$ crise que se abre no início dos anos 80 , com origem num colapso financeiro que atinge diversos países e num redirecionamento político e econômico norte-americano, abre-se um período em que a agenda pública no Brasil é disputada entre segmentos liberaldemocráticos e os interesses ligados às finanças internacionais e os bancos brasileiros com forte posição no mercado.

Esse conflito acaba sendo decidido, em meados da década de 90, num movimento complexo que envolve privatizações, desnacionalização de grandes empresas brasileiras, forte desaceleração do emprego e da renda, fragilização dos sindicatos e dos movimentos populares e a irrupção de uma cultura individualista e midiática que enfraquece a solidariedade social e redireciona a ação pública.

Embora seja difícil fazer uma política macroeconômica criativa nos quadros do atual conjunto de interesses dominantes no plano internacional, que são basicamente financeiros, o Brasil optou por um ajuste fiscal e financeiro que restringiu sem necessidade ações importantes como aquelas voltadas para a democratização do acesso ao solo urbano e rural, seguridade social mais abrangente e gastos mais audaciosos em saúde e educação. Na verdade a macroeconomia se torna refém dos interesses privados e a passagem à democracia convertese numa privatização do estado paradoxal.

No âmbito estadual, a progressiva deterioração das finanças públicas convive com abandono da disciplina fiscal e com elevação dos níveis de endividamento. Altera-se também o quadro institucional do setor público paranaense com o processo de privatização de empresas públicas estaduais setores de infra-estrutura preludiado pela extinção do Badep. A partir de meados da década de 90, esse quadro reflete um governo que altera a máquina pública e a inserção do governo estadual na sociedade paranaense de forma marcante.

No início deste século, o governo estadual passa a enfrentar dificuldades financeiras que extinguem órgãos e cargos ligados ao executivo, inclusive secretarias e autarquias, tornando visível a dificuldade de manejo financeiro das atividades do governo.

Também em meados dos anos 90, o governo estadual concede um amplo conjunto de vantagens e benefícios fiscais e financeiros destinados a atrair principalmente empresas multinacionais do setor automobilístico. Houve também benefícios relativos à infra-estrutura com envolvimento da Copel e da Sanepar, além da construção de um ramal ferroviário entre a empresa e o tronco ferroviário mais próximo. Além disso, o governo do estado manteve participação acionária na rede de distribuição da Renault usando recursos do Fundo de Desenvolvimento Econômico (FDE) provenientes de royalties, venda de ações da Copel e 
créditos do extinto Badep. A Renault recebeu recursos a título de empréstimos com prazo de vencimento de 10 anos, sem juros ou atualização monetária e deverá pagar os empréstimos a partir de 2006. Benefícios também foram estendidos a outras empresas automobilísticas e seus fornecedores. Tudo isso ocorreu no contexto já aludido da guerra fiscal.

A conclusão sobre a execução de políticas de desenvolvimento estaduais autônomas e agressivas pela via da guerra fiscal é clara: a degradação do espaço federativo impõe um custo nacional maior do que as eventuais vantagens regionais obtidas com a realização dos investimentos. Além do mais, cria-se a idéia de que o país faz com que seu território passe por períodos tormentosos perante qualquer espasmo de investimentos.

Este conjunto de processos econômicos e opções políticas realizadas limitam em muito a ação pública no Brasil. No atual governo estadual assiste-se a uma luta para recuperar alguns espaços de elaboração e execução de políticas públicas que foram perdidos no ciclo anterior. Entretanto, não deve o leitor acreditar que a conjuntura é favorável a uma ação que tende a contestar os contratos tão centrais na retórica dominante entre os formuladores de política econômica a nível nacional.

O governo estadual tem se mostrado inventivo, como no caso do combate aos transgênicos, à política de concessões de serviços públicos, tem revitalizado órgãos de ensino e pesquisa e se mostrado corajoso em suas posições diante da agenda macroeconômica federal. Essas ações são ponto de partida contra a paralisia a que as opções dos anos 90 empurraram à sociedade, à política e até mesmo ao empresariado no Paraná. No entanto, pensamos que outros desafios deveriam ser incluídos na agenda pública estadual.

Entre eles, os autores propõem que os agentes sociais privados e públicos presentes no estado do Paraná passem a encarar o desafio de conquistar o "mercado brasileiro" que, afinal de contas, apresenta menos barreiras à entrada do que os mercados externos. Complementarmente, seria extremamente auspicioso que o estado, através da sua inteligência constituída, passasse a preocupar-se com as relações federativas e os termos que podem pautar a inserção do Paraná no espaço nacional, reinventando conjuntamente com outras unidades políticas a idéia de construção da nação e não a de meramente tentar incluir-se como uma ilha de prosperidade em meio a um mar muito encapelado. 